\title{
Clinical characterization and therapeutic targets of vitamin A in patients with hepatocholangiocarcinoma and coronavirus disease
}

\author{
Xiao Liang ${ }^{1,3,}{ }^{*}$, Rui Zhou ${ }^{2, *}$, Yu Li ${ }^{1,3}$, Lu Yang ${ }^{1,3}$, Min Su ${ }^{1,3}$, Keng Po Lai ${ }^{1,3}$ \\ ${ }^{1}$ Laboratory of Environmental Pollution and Integrative Omics, Guilin Medical University, Guilin, Guangxi, China \\ ${ }^{2}$ Department of Hepatobiliary Surgery, Guigang City People's Hospital, The Eighth Affiliated Hospital of Guangxi \\ Medical University, Guigang, Guangxi, China \\ ${ }^{3}$ Guangxi Key Laboratory of Tumor Immunology and Microenvironmental Regulation, Guilin Medical University, \\ Guilin, Guangxi, China \\ *Equal contribution
}

Correspondence to: Min Su, Keng Po Lai; email: Susan sumin@glmc.edu.cn, kengplai@glmc.edu.cn Keywords: hepatocholangiocarcinoma, coronavirus disease, COVID-19, vitamin A, network pharmacology, bioinformatics Received: February 16, 2021

Accepted: June 4, 2021

Published: June 27, 2021

Copyright: (C) 2021 Liang et al. This is an open access article distributed under the terms of the Creative Commons Attribution License (CC BY 3.0), which permits unrestricted use, distribution, and reproduction in any medium, provided the original author and source are credited.

\section{ABSTRACT}

Recent reports indicate that patients with hepatocholangiocarcinoma (CHOL) have a higher morbidity and mortality rate for coronavirus disease (COVID-19). Anti-CHOL/COVID-19 medicines are inexistent. Vitamin A (VA) refers to a potent nutrient with anti-cytotoxic and anti-inflammatory actions. Therefore, this study aimed to determine the potential functions and molecular mechanisms of VA as a potential treatment for patients with both CHOL and COVID-19 (CHOL/COVID-19). The transcriptome data of CHOL patients were obtained from the Cancer Genome Analysis database. Furthermore, the network pharmacology approach and bioinformatics analysis were used to identify and reveal the molecular functions, therapeutic biotargets, and signaling of VA against CHOL/COVID-19. First, clinical findings identified the medical characteristics of CHOL patients with COVID-19, such as susceptibility gene, prognosis, recurrence, and survival rate. Anti-viral and anti-inflammatory pathways, and immunopotentiation were found as potential targets of VA against CHOL/COVID-19. These findings illustrated that VA may contribute to the clinical management of CHOL/COVID-19 achieved by induction of cell repair, suppression of oxidative stress and inflammatory reaction, and amelioration of immunity. Nine vital therapeutic targets (BRD2, NOS2, GPT, MAPK1, CXCR3, ICAM1, CDK4, CAT, and TMPRSS13) of VA against CHOL/COVID-19 were identified. For the first time, the potential pharmacological biotargets, function, and mechanism of action of VA in CHOL/COVID-19 were elucidated.

\section{INTRODUCTION}

Coronavirus disease (COVID-19) is a worldwide spread disease, caused by severe acute respiratory syndrome coronavirus 2 (SARS-CoV-2) [1]. Increasing epidemiological data shows that the prevalence, mortality rate, and spread of COVID-19 is rising rapidly worldwide, especially in the United States [2]. There is currently no effective treatment for COVID-19 [3]. Despite the ongoing studies for the development of a COVID-19 vaccine by researchers, the clinical effectiveness of vaccine remains undetermined [4]. Accordingly, there is an urgent need for further research to develop effective bioactive ingredients to treat COVID-19. On the other hand, increasing evidence indicates that cancer patients may be high risk in SARS$\mathrm{CoV}-2$ infection, with a high death rate [5]. Hepatocholangiocarcinoma (CHOL) is a rare type of hepatic carcinoma characterized by its high invasion and metastasis potential [6]. According to the cancer statistics of China, liver cancer, including CHOL, is the leading cause of cancer-related deaths [7]. Hospitals are 
high-risk places for SARS-CoV-2 infection and transmission in early outbreaks due to the hard-todiagnose symptoms of this new virus [8]. Accordingly, the CHOL patients in the hospital may have a higher risk of exposure to SARS-CoV-2. Therefore, it can be difficult to treat patients with both CHOL and COVID19 (CHOL/COVID-19), and the fatality rate is high given the absence of an effective treatment [9-11]. Therefore, there is a need to develop a specific treatment targeting CHOL/COVID-19 patients.

Vitamin A (VA), a functional nutrient, is necessary for normal vision and has anti-inflammatory properties [12] VA facilitates growth and reproduction, maintains bones and epithelial tissue, and aids in mucosal epithelium secretion [13]. Further, VA supplementation can prevent precancerous lesions [14]. In VA deficiency, the epithelial cells in the respiratory tract are keratinized, resulting in reduced immunity and an increased risk of infection [15]. VA regulates different gene targets through nuclear receptors, leading to improve immune system and induce the production of cytokines by immune cells $[16,17]$. VA has antiviral and antitumor properties, as it is extremely important in maintaining a sufficient level of natural killer cells in circulating blood [18]. In vitro studies show that a high dose of VA may have anti-tumor effects in human cancer cell lines [19]. Clinical findings indicate that high-dose intake of VA may reduce the risk of liver cancer in the Chinese population [20]. However, the association between VA and CHOL remains unknown. In addition, the therapeutic action and mechanism of VA in CHOL/COVID-19 have still not been reported. As an attractive strategy, network pharmacology is an effectual approach for uncovering the putative, vital target, function, and pathway of bioactive ingredients against clinical disorders [21, 22]. Our previous bioinformatics findings revealed all vital targets, pharmacological functions, and molecular mechanisms of some bioactive compounds in complex diseases, including hepatic carcinoma, sepsis, and pneumonia [23-25]. Therefore, in this report, using the network pharmacology approach, we aimed to identify and characterize the mechanism underlying antiCHOL/COVID-19 pharmacological activity of VA. The finding of this study would provide an alternative approach to use vitamin A as a supplement to boost up the efficiency of the existing vaccines for $\mathrm{CHOL} /$ COVID-19 treatment.

\section{MATERIALS AND METHODS}

\section{Collection of CHOL/COVID-19-related genes}

In order to determine the CHOL/COVID-19-associated genes, we obtained the transcriptome dataset of CHOL patients from the Cancer Genome Atlas (TCGA) database (https://portal.gdc.cancer.gov/) on July 25, 2020 as previous described [23]. The differentially expressed genes in $\mathrm{CHOL}$ patients were identified using the "limma" package of $\mathrm{R}$ language Bioconductor (with a false discovery rate $<0.05$ and $\left|\log { }^{\text {fold change }(\mathrm{FC})}\right|>1$ ). Then, COVID-19-associated genes were obtained from different databases including the Genecard database, Online Mendelian Inheritance in Man (OMIM) database, and National Center for Biotechnology Information (NCBI) gene function module. Then, the CHOL- and COVID-19-associated genes were compared and overlapped as previous descried [26].

\section{Clinicopathological analysis of CHOL and COVID- 19-related genes}

The survival rates of the CHOL patients were correlated to CHOL/COVID-19-associated genes using the "survival" package in $\mathrm{R}$ as previous described [23]. Then the univariate and multivariate Cox proportional hazards regression analyses were used to determine the prognostic value of CHOL/COVID-19-associated genes. Finally, the patients were classified as low- and high-risk groups based on the average risk score as previous described [27].

\section{Determination of VA-pharmacological target in CHOL/COVID-19}

In an attempt to determine the targets of VA, we searched online databases and tools, including the Traditional Chinese Medicine Systems Pharmacology Database and Analysis Platform (TCMSP), Swiss Target Prediction, TargetNet, Batman, Drugbank, and HitPick. The genes were used to compare with CHOL/COVID-19-associated genes. The overlapped genes were corrected using Swiss-Prot and the UniProt database with human settings as previous described $[28,29]$.

Gene ontology enrichment and gene networking analyses of VA against CHOL/COVID-19-associated genes

The identified VA/CHOL/COVID-19-associated genes were subjected to Gene Ontology (GO) enrichment analysis and Kyoto Encyclopedia of Genes and Genomes (KEGG) pathways using $\mathrm{R}$ language packages. GO terms with and $p$ value $<0.05$ were considered as statistically significant. The association between VA/CHOL/COVID-19-associated genes, GO terms, and pathways was visualized using Cytoscape software (3.7.1 version) as previous described [21, 30]. Then the identified genes were subjected to the STRING database (version 11.0) for 
gene networking analysis to determine the proteinprotein interactions (PPI) network map as previous described [31, 32].

\section{Metabolic pathway analysis}

MetaboAnalyst 4.0 was used to analyze the metabolic pathway using the treatment targets of VA against CHOL/COVID-19. Further, the anti-CHOL/COVID-19 metabolic pathways were obtained using parameter determination in the metabolic pathway (integrated) database [33].

\section{RESULTS}

\section{Collection of CHOL/COVID-19-associated genes}

Using the network pharmacology approach, we identified 458 genes associated with COVID-19 (Figure 1A). Meanwhile, 15,246 common differential expressed genes in CHOL patients were obtained from the TCGA database (Figure 1A). When we compared these two gene clusters, we found 263 overlapping genes between COVID-19 and CHOL patients (Figure 1A), in which, 221 genes were up-regulated and 42 genes were downregulated in CHOL patients (Figure 1B).

\section{Clinical and medical analyses of CHOL/COVID-19- associated genes}

To further reveal the clinical characteristics and the clinicopathological value of CHOL/COVID-19associated genes, the 263 differential genes were subjected to univariate and multivariate Cox analyses. The univariate Cox analysis highlighted that 7 genes (including MRC1, CP, ITGA5, SNCA, HARS1, ENPP1, and $P L A U)$ were significantly $(p<0.05)$ associated with CHOL/COVID-19 (Figure 2A and Table 1). Additionally, multivariate Cox analysis identified 3 target genes CP, HARS1, and PLAU (Table 2). The patients were divided into high- and low-risk groups based on the coefficient values of multivariate Cox proportional hazards regression analysis (Figure 2B and Table 2). In addition, we found a greater risk value in patients correlated with a higher risk score (Figure 2C) and it is related to the increased expression levels of CP, HARS1, and PLAU (Figure 2D). Furthermore, we conducted an independent single factor and multifactor prognostic analysis with the 3 genes. In the survival analysis, the data showed that the high- and low-risk groups related to these 3 genes had a significant impact on the overall survival (Figure 2E). Moreover, we also performed a univariate and multivariate independent prognostic analysis of the 3 genes. The difference in the independent prognostic analysis of the risk value was significant $(\mathrm{p}<0.05)$, and the hazard ratio was greater than 1 , indicating that as the risk value increases, the prognostic risk increases too. These results could be used as independent prognostic analysis factors for CHOL/COVID-19 (Table 3). The clinical correlation analysis of the 3 genes was carried out, and the results showed that there was no correlation between each gene and a single clinical factor (Table 4).

\section{Harvesting VA targets and intersection with COVID-19 and CHOL}

217 VA-related targets were obtained from the UniProt database. When we compared the CHOL/COVID-19associated genes with VA-targeted genes, we identified 9 overlapping genes (Figure 3A and Supplementary Table 1). These 9 intersection genes were submitted to
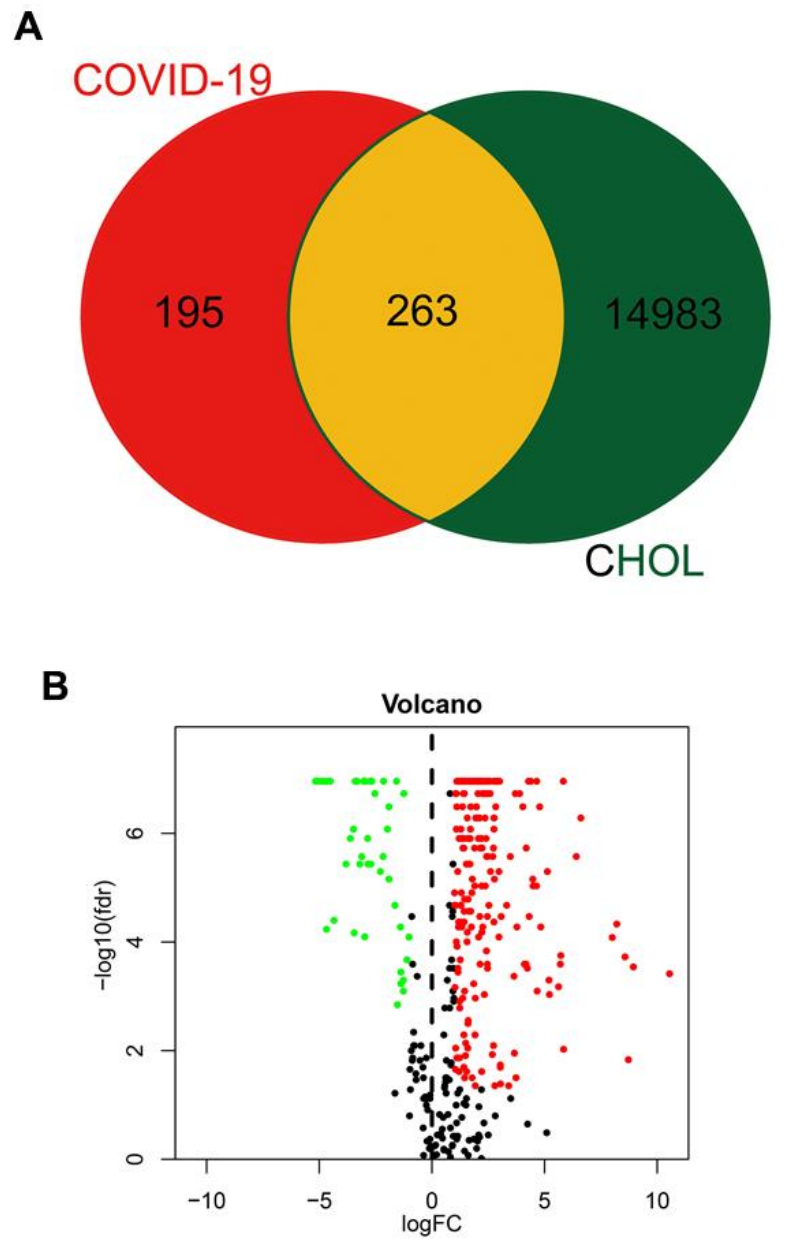

Figure 1. Identification of CHOL/COVID-19-assocaited genes. (A) Venn diagram depicted the number of intersecting genes in CHOL/COVID-19. (B) Volcano-plot showed the expression level of differential expressed genes (DEGs) found in $\mathrm{CHOL}$. The genes with $\mid \log 2$ (fold change) $\mid>1$ and $-\log 10(\mathrm{FDR})>$ 1.3 were considered as DEGs. 
GO and KEGG enrichment analyses, the results showed that VA affected several biological processes related to oxygen level such as response to hypoxia, response to hyperoxia, and metabolic/biosynthetic process of reactive oxygen species. Also, our results highlighted $\mathrm{T}$ cell migration, peroxisomal protein targeting, protein localization to peroxisome, establishment of protein localization to peroxisome, peroxisomal transport, regulation of leukocyte-mediated cytotoxicity, peroxisome organization, regulation of DNAbinding transcription factor activity, regulation of cell killing, lymphocyte migration, neurotransmitter metabolic process, cell killing, regulation of leukocyte migration, and cellular response to interferon-gamma (Figure 3B, 3C and Supplementary Table 2). In the KEGG pathway analysis, 35 pathways related to Influenza A, Kaposi sarcoma-associated herpesvirus infection, human T-cell leukemia virus 1 infection, toxoplasmosis, hepatitis C, Epstein-Barr virus infection, viral carcinogenesis, peroxisome, $\mathrm{T}$ cell receptor signaling pathway, natural killer cell- mediated cytotoxicity, hypoxia-inducible factor-1 signaling pathway, tumor necrosis factor (TNF) signaling pathway, relaxin signaling pathway, FOXO signaling pathway, apelin signaling pathway, and chemokine signaling pathway were identified (Figure 3D, 3E and Supplementary Table 3). As a result, the network visualization of VA/CHOL/COVID-19 mediated biological processes and KEGG pathways was plotted using Cytoscape 3.7.1, as shown in Figure $3 \mathrm{~F}$.

\section{Identifying core targets of VA against CHOL and COVID-19}

The 9 intersection targets of VA against CHOL/COVID-19 were subjected to STRING analysis to understand the protein-protein interaction (Figure 4A). Furthermore, six core gene targets including $C A T$, NOS2, CXCR3, MAPK1, GPT, and ICAM1 of VA against CHOL/COVID-19 were identified using Cytoscape tool (Figure 4B).

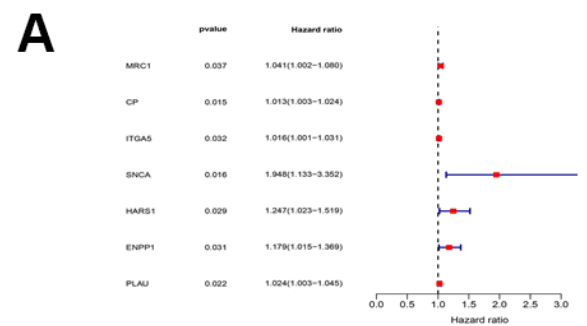

B
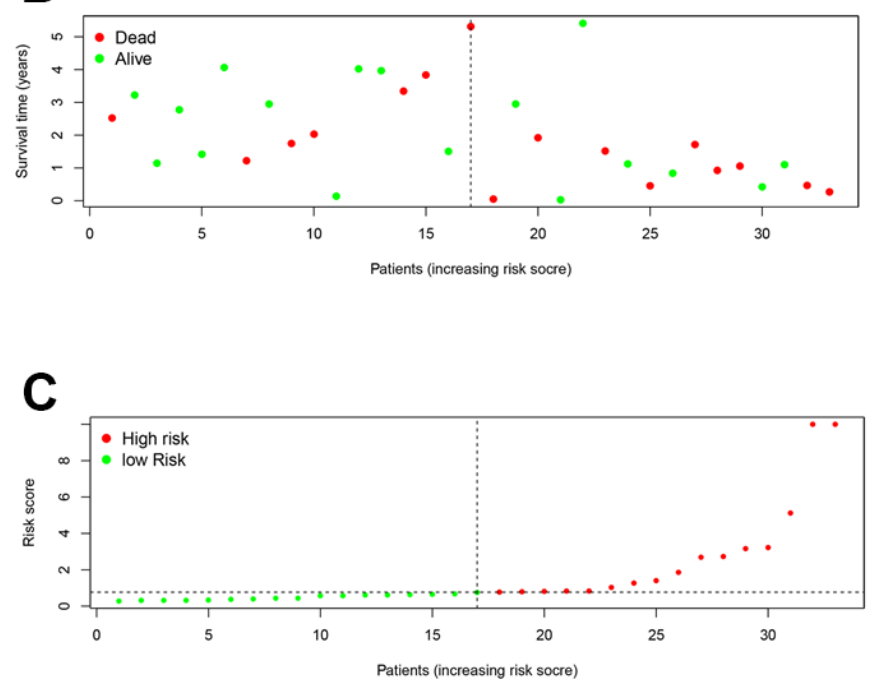

D

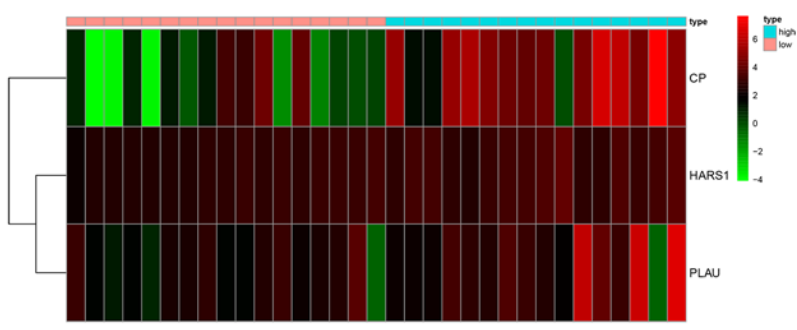

E

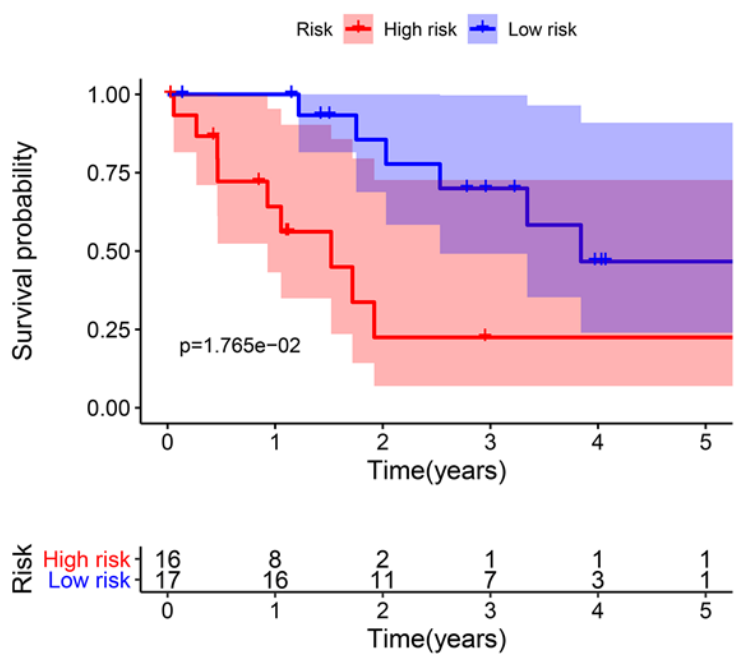

Figure 2. Prognostic value of CHOL/COVID-19-associated genes. (A) Univariate Cox analysis of 7 CHOL/COVID-19-associated genes, including MRC1, CP, ITGA5, SNCA, HARS1, ENPP1, and PLAU. $(p<0.05)$. Hazard ratio represented the correlation of the identified genes and $\mathrm{CHOL}$. (B) Survival analysis indicated no difference in the overall survival between high- and low-risk groups of $\mathrm{CHOL}$ patients. (C) Analysis of patients' risk score using Cox proportional hazards regression showed the increasing risk score in the CHOL patients with high risk. (D) Heatmap showed the overexpression of CP, HARS1 and PLAU in the CHOL patients with high risk as compared to those with low risk. (E) The $\mathrm{CHOL}$ patients from high-risk group had a poor overall survival rate as compared to those from low-risk group. 
Table 1. Univariate Cox proportional hazards regression analysis of CHOL/SARS-CoV-2 gene.

\begin{tabular}{lcccc}
\hline Symbol & HR & HR.95L & HR.95H & pvalue \\
\hline MRC1 & 1.0405 & 1.0023 & 1.0802 & 0.0375 \\
CP & 1.0132 & 1.0025 & 1.0241 & 0.0155 \\
ITGA5 & 1.0163 & 1.0014 & 1.0313 & 0.0316 \\
SNCA & 1.9485 & 1.1326 & 3.3522 & 0.0160 \\
HARS1 & 1.2468 & 1.0233 & 1.5191 & 0.0286 \\
ENPP1 & 1.1789 & 1.0151 & 1.3690 & 0.0310 \\
PLAU & 1.0241 & 1.0034 & 1.0451 & 0.0222 \\
\hline
\end{tabular}

Table 2. Multivariate Cox proportional hazards regression analysis.

\begin{tabular}{lcccc}
\hline Symbol & coef & HR & $\mathbf{9 5 \%}$ CI & pvalue \\
\hline CP & 0.0148 & 1.015 & $1.003-1.0271$ & 0.014 \\
HARS 1 & 0.2251 & 1.2525 & $1.0056-1.56$ & 0.0445 \\
PLAU & 0.024 & 1.0243 & $1.0028-1.0463$ & 0.0265 \\
\hline
\end{tabular}

Table 3. Univariate analysis and multivariate analysis of the correlation of three differentially expressed genes with overall survival (OS) among the patients.

\begin{tabular}{|c|c|c|c|c|c|c|}
\hline \multirow{2}{*}{ Parameter } & \multicolumn{3}{|c|}{ Univariate analysis } & \multicolumn{3}{|c|}{ Multivariate analysis } \\
\hline & HR & $95 \% \mathrm{CI}$ & pvalue & HR & $95 \% \mathrm{CI}$ & pvalue \\
\hline gender & 1.0997 & $0.3463-3.4925$ & 0.8720 & 1.2914 & $0.2859-5.8327$ & 0.7396 \\
\hline Stage(Stage I- Stage IV) & 1.1708 & $0.7421-1.847$ & 0.4979 & 2.4575 & $0.2699-22.3759$ & 0.4250 \\
\hline $\mathrm{T}(\mathrm{T} 1-\mathrm{T} 4)$ & 1.2231 & 0.6104-2.4509 & 0.5700 & 0.6070 & $0.0537-6.857$ & 0.6866 \\
\hline $\mathrm{M}(\mathrm{M} 0-\mathrm{M} 1)$ & 0.6067 & $0.0776-4.7458$ & 0.6340 & 0.2070 & $0.0119-3.6046$ & 0.2799 \\
\hline $\mathrm{N}(\mathrm{N} 0-\mathrm{N} 1)$ & 1.5266 & $0.3161-7.3722$ & 0.5985 & 0.4902 & $0.0107-22.5015$ & 0.7150 \\
\hline riskScore & 1.2421 & 1.0524-1.466 & 0.0104 & 1.2268 & $1.0226-1.4718$ & 0.0278 \\
\hline
\end{tabular}

Table 4. Clinical correlation analysis.

\begin{tabular}{|c|c|c|c|c|c|}
\hline Symbol & Gender (male vs female) & Stage (stage I and II vs stage III and IV) & $\mathrm{T}(\mathrm{T} 1$ and 2 vs T3 and 4) & M (M0 vs M1) & N (N0 vs N1) \\
\hline $\mathrm{CP}$ & $-0.463(0.649)$ & $0.057(0.956)$ & $-0.181(0.863)$ & $1.53(0.151)$ & $-0.417(0.699)$ \\
\hline HARS1 & $0.446(0.659)$ & $1.181(0.265)$ & $0.418(0.684)$ & $0.843(0.453)$ & $2.063(0.092)$ \\
\hline PLAU & $0.295(0.770)$ & $-0.91(0.401)$ & $-0.924(0.405)$ & $-0.859(0.479)$ & $-1.023(0.379)$ \\
\hline Risk Score & $-1.425(0.156)$ & $-1.48(0.141)$ & $-2.172(0.031)$ & $-1.507(0.137)$ & $-1.507(0.134)$ \\
\hline
\end{tabular}

Findings of metabolic pathways in intersection targets

Using the MetaboAnalyst tool, it was observed that the metabolic pathways of VA against CHOL/COVID-19 were involved in arginine biosynthesis; glyoxylate and dicarboxylate metabolism; alanine, aspartate, and glutamate metabolism; arginine and proline metabolism, and tryptophan metabolism (Figure 5).

\section{DISCUSSION}

SARS-CoV-2, a new fatal virus, is of great concern in human health domain since its outbreak. This virus has spread rapidly without any national boundary, causing several deaths and economic losses [34, 35]. Although some vaccines against SARS-CoV-2 are available, their efficiencies still varied. Thus, the risk of infection and death from COVID-19 is still a global health problem 
A

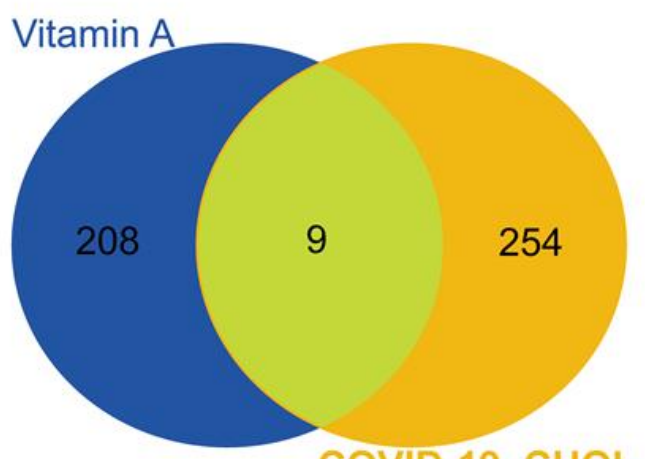

B

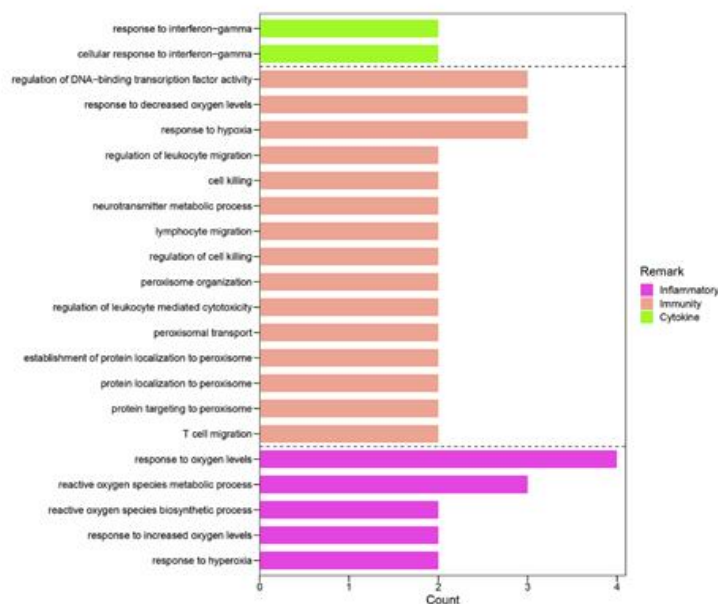

E

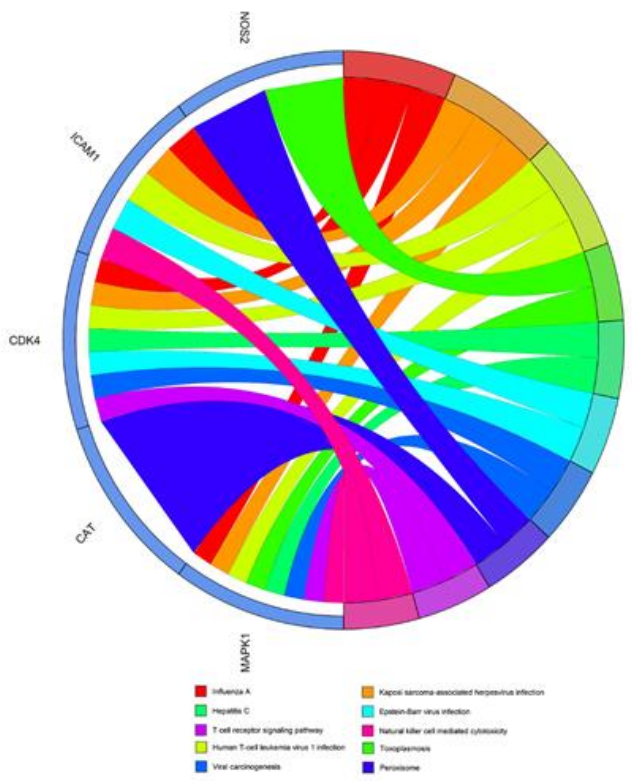

C

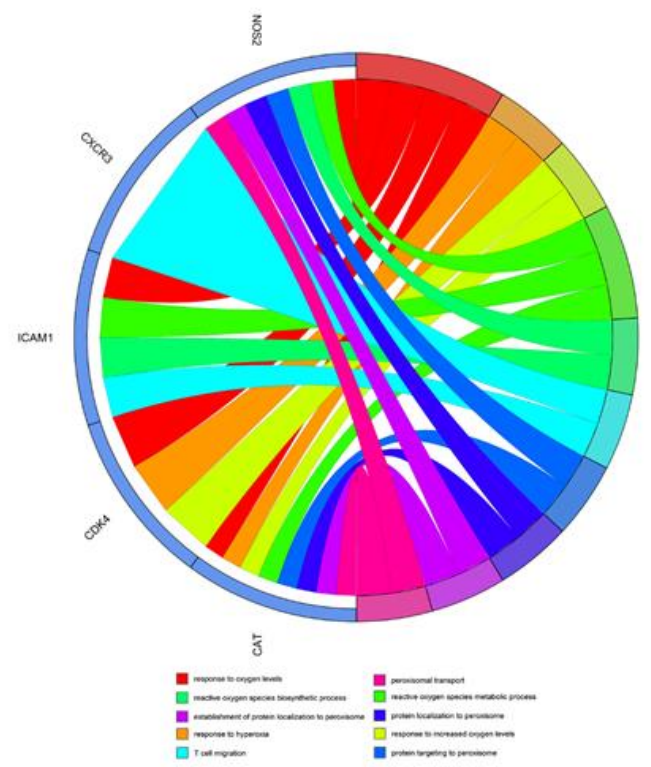

D

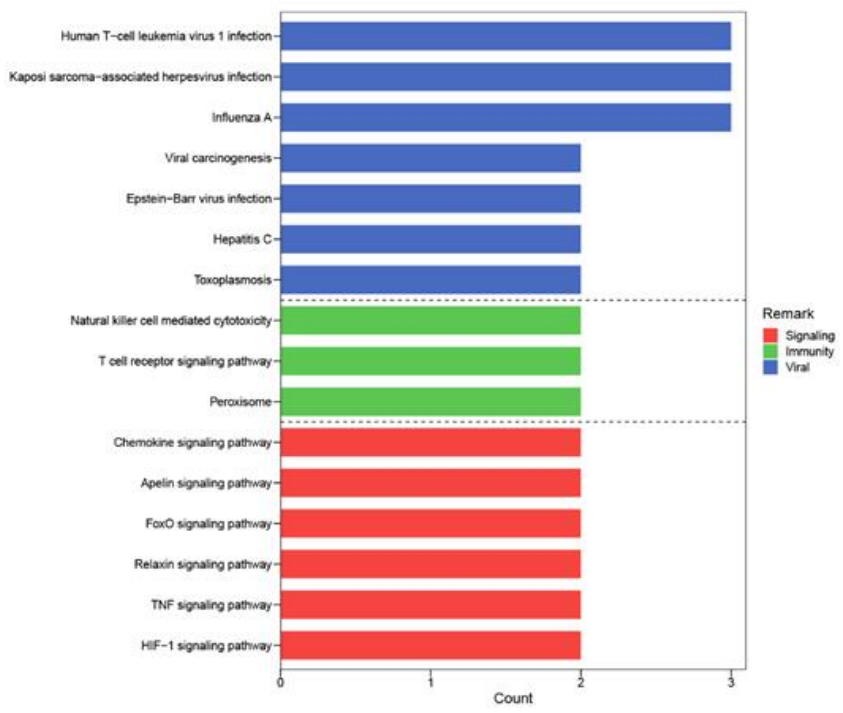

$\mathbf{F}$

G0.0072663 G0.0072662 G0.0001906 60.0072593 60.0055093 G0.0070482 60.0072678 60.007134 60.000268560 .0072676 60.0001910 60:1903409 $60.000652560 .004213360: 0007031600051090$ G0.0031341 G0:0036296 G0:0034341 G0.0036293 60.000166660 .0043574

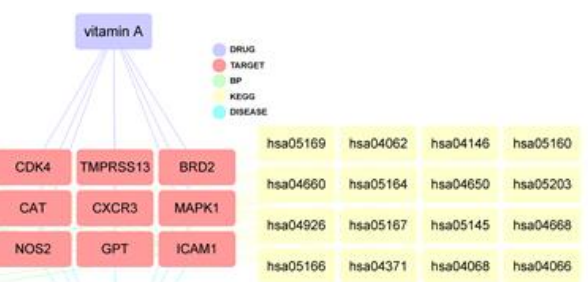

COVID-19_CHOC

Figure 3. Identification and functional characterization of CHOL/COVID-19/Vitamin A-associated genes. (A) Venn diagram showed the number of intersecting genes of vitamin A and CHOL/COVID-19. (B) Gene ontology enrichment analysis highlighted the biological processes affected by the VA/CHOL/COVID-19-associated genes. (C) The bubble diagram showed the involvement of genes in different biological processes. (D) Kyoto Encyclopedia of Genes and Genomes (KEGG) pathway analysis demonstrated the alteration of cell signaling pathways by the VA/CHOL/COVID-19-associated genes. (E) The bubble diagram showed the involvement of genes in different cell signaling pathways. (F) Interaction network showed core biotargets, pharmacological functions, and signaling pathways of VA against CHOL/COVID19.VA. 
[9]. In recent decades, chronic diseases, including cancers, are increasing yearly worldwide [36]. Cancer patients are immunosuppressed and have a heterogeneous immunity [37], leading to an increased risk for other infections. Hospital-acquired COVID-19 is increasing due to the high risk and exposure, especially in less-developed countries/areas [38]. In the 2020 cancer statistics, liver cancer is the main leading cause of cancer-related deaths in the United States and China [39]. As reported, the COVID-19 prevalence and deaths in the United States are increasing [40]. Accordingly, the patients with CHOL are at a high risk of being infected with SARS-CoV-2 due to the absence of an effective treatment. In addition, the therapeutic efficacy of existing pharmacotherapy will be further reduced in patients with simultaneous CHOL and COVID-19, resulting in an increase in the death rate.

It has been suggested that VA has an anti-proliferative property against liver cancer cells [41]. Moreover, given the potential anti-infective action of VA, it has been
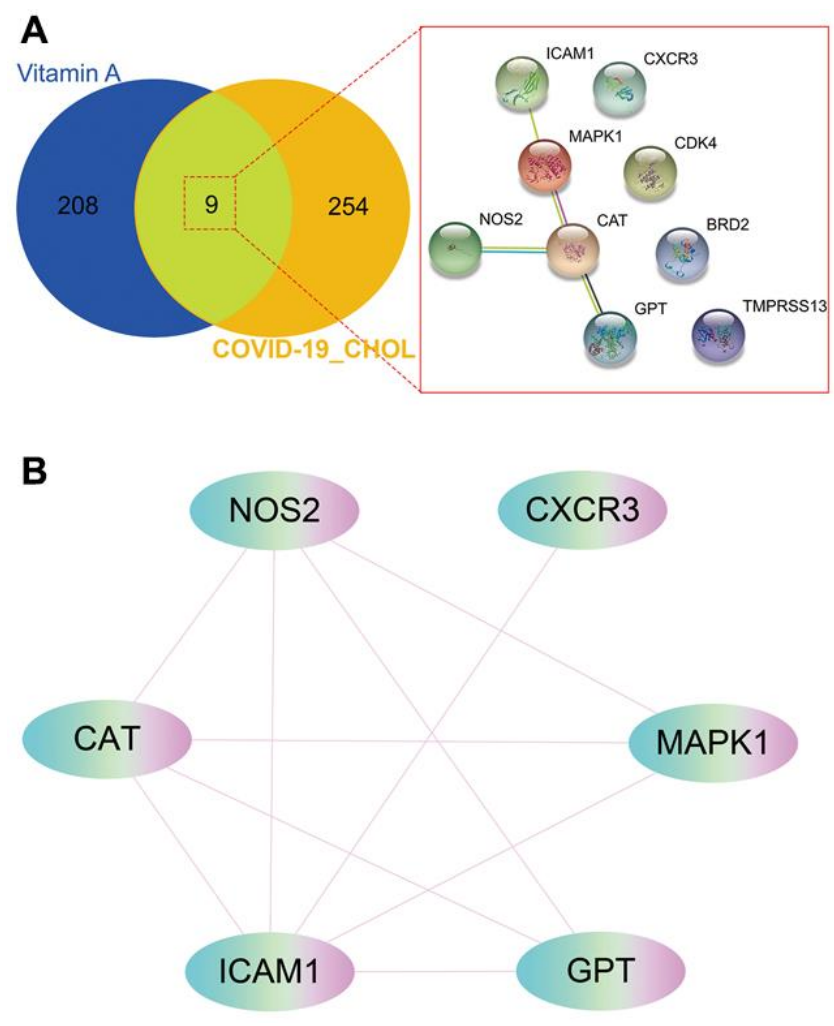

Figure 4. Gene network analysis of vitamin A against CHOL/COVID-19. (A) STRING analysis indicated protein-protein interaction mediated by 9 intersecting genes of VA against CHOL/COVID-19. (B) Cytoscape analysis further showed the involvement of 6 core candidates including CAT, NOS2, CXCR3, MAPK1, GPT, and ICAM1 in protein interaction network related to action of VA against CHOL/COVID-19. hypothesized that VA is likely effective in CHOL patients infected with SARS-CoV-2. In this bioinformatics analysis, all putative and core genes, and 263 mapped genes of CHOL/COVID-19 were identified. The DGE analysis showed 221 up-regulated and 42 down-regulated genes in patients with $\mathrm{CHOL}$ and/or COVID-19, suggesting the biomarkers for clinical characterization of $\mathrm{CHOL}$ patients with COVID-19. As per the independent prognostic and survival analyses, few of the important differentially expressed genes, including $M R C 1, C P$, ITGA5, SNCA, HARS1, ENPP1, and PLAU may function as potent biomarkers for screening and characterizing different stages of CHOL patients with COVID-19. For instance, mannose receptor C-type 1 (MRC1) is a C-type lectin present on the surface of macrophages [42]. Genomewide association studies demonstrated the importance of MRC1 in both of innate and adaptive immunity [43]. In addition, MRC1 coordinated with the activation of STAT6 for the differentiation of monocytes into monocyte-derived macrophages [44]. Integrin Subunit Alpha 5 (ITGA5), a family member of integrin alpha chain, plays role in cell-surface mediated signaling [45]. It has been reported that ITGA5 was a new candidate for SARS-CoV-2 cell binding and entry [46]. A transcriptome profile analysis also showed the overexpression of ITGA5 in lung samples from COVID-19 patients [47]. Synuclein Alpha (SNCA), a synuclein protein, is abundant in presynaptic terminals [48]. It has been reported the protective role of SNCA against SARS-CoV-2 infections in patients with Parkinson's disease [49].

Using the network pharmacology approach, we further identified 9 intersection genes of VA/CHOL/COVID19. Moreover, the expression of ICAM1, NOS2, and CAT was increased in CHOL/COVID-19, while the survival rate was low, although these genes were only marginally increased. But it has been reported that these genes were contributed to the tumorigenicity of liver cancer. For instance, catalase (CAT) a key antioxidant enzyme defense against oxidative stress which played important role in the development of many cancer types [50]. Intercellular Adhesion Molecule 1 (ICAM1) is an oncogene of liver cancer. A microarray study of liver cancer patients showed that ICAM1 axis is necessary for tumor immune evasion and the tumorigenesis of liver cancer [51]. RNA-seq analysis revealed downregulation of the MAPK/ERK pathway through the downstream effectors ICAM1, leading to suppress tumor growth and increase chemosensitivity of liver cancer toward chemotherapy [52]. ICAM1 inhibition could suppresses tumor growth and metastasis [53]. A prospective cohort study of 282 patients with liver disease also demonstrated the association of soluble serum ICAM1 and liver cancer development [54]. 
Another clinicopathological study of 236 liver cancer patients suggested that ICAM promoted liver cancer metastasis and high serum ICAM1 level had shorter DFS and OS after resection in patients with liver cancer [55]. Nitric oxide synthase 2 (NOS2) was mainly expressed in liver and was found to provide crucial signals for angiogenesis in the tumor microenvironment [56]. It has been reported that the presence of NOS2 in mitochondria of liver cancer cells was associated with more aggressive phenotypes of cancer cells [57]. Because NOS2 was closely correlated with chronic inflammation and hepatocarcinogenesis in liver cancer [58]. These results suggested that the identified intersection genes may serve as pharmacological targets of VA against CHOL and COVID-19.

Lastly, the metabolic analysis highlighted some possible alterations of metabolic pathways in CHOL/COVID-19 patients. For instance, arginine biosynthesis and metabolism were found to be deregulated in our analysis. Arginine is an $\alpha$-amino acid that is used for the protein synthesis. It was reported that accumulation of arginine metabolites by liver cancer cells is an important feature of non-alcoholic steatohepatitisassociated hepatocarcinogenesis [59]. A metabolomic study in mouse also demonstrated the arginine dynamics during hepatocellular carcinoma progression [60], suggesting the importance of arginine in the development of liver cancer. Other than arginine, tryptophan metabolism was also found to be induced in our analysis. It was concordant to the published literature that tryptophan was dramatically increased in liver cancer patients compared with healthy subjects [61]. And tryptophan metabolism was reported to be associated with metastasis and invasion of liver cancer [62].

The results of GO and KEGG enrichment analysis showed that the effects of VA on anti-CHOL and antiCOVID-19 were mainly through the regulation of

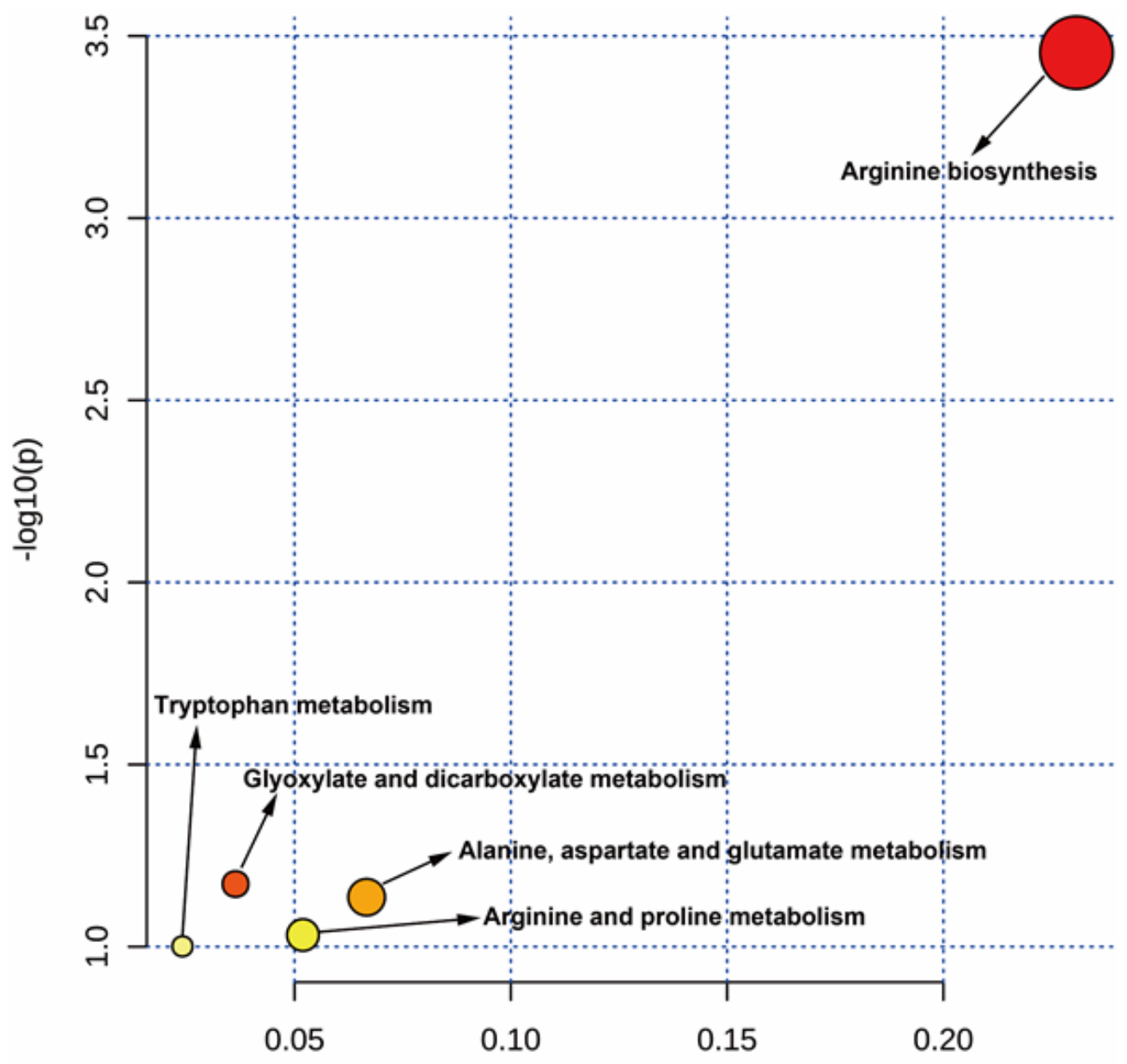

Pathway Impact

Figure 5. MetaboAnalyst analysis showed the targeted metabolic pathways by VA against CHOL/COVID-19. 
immune responses such as anti-viral and antiinflammatory actions, immunoregulation, influenza A, human T-cell leukemia virus 1 infection, viral carcinogenesis, $\mathrm{T}$ cell receptor signaling, natural killer cell-mediated cytotoxicity, TNF signaling, and chemokine signaling. Additionally, the anti-CHOL/COVID-19 effect of VA was controlled by 3 core genes, including ICAMI, $N O S 2$, and CAT, suggesting the possible therapeutic and immunotherapeutic targets for treating COVID-19 or CHOL/ COVID-19.

\section{CONCLUSIONS}

This study uncovers potential targets/pathways of VA treatment in CHOL/COVID-19, including the anti-viral and anti-inflammatory pathways, and immunopotentiation. This report, for the first time, suggested that VA is an alternative option for treating CHOL/COVID-19. However, further clinical studies are necessary to secure the clinical use of VA against CHOL/COVID-19.

\section{Abbreviations}

CHOL: hepatocholangiocarcinoma; SARS-CoV-2: severe acute respiratory syndrome coronavirus 2; COVID-19: Coronavirus Disease 2019; TCGA: The Cancer Genome Atlas; GO: Gene Ontology; BP: Biological process; KEGG: Kyoto Encyclopedia of Genes and Genomes; RMSD: root mean square deviation; TCMSP: Traditional Chinese Medicine Systems Pharmacology Database and Analysis Platform.

\section{AUTHOR CONTRIBUTIONS}

L.X, K.P.L. and M.S. conceived and designed the study. R.Z. and Y.L. performed the data analysis and data interpretation. Y.L. and X.L. conducted the bioinformatics and statistical analyses. R.L and K.P.L prepared the manuscript.

\section{ACKNOWLEDGMENTS}

Keng Po Lai is supported by Hong Kong SAR, Macao SAR and Taiwan Province Talent Young Scientist Program of Guangxi.

\section{CONFLICTS OF INTEREST}

The authors declare that they have no conflicts of interest.

\section{FUNDING}

This study is supported by the National Natural Science Foundation of China (No. 81660091) and the National
Natural Science Foundation of Guangxi (No. 2018GXNSFAA281242).

\section{REFERENCES}

1. Lai CC, Shih TP, Ko WC, Tang HJ, Hsueh PR. Severe acute respiratory syndrome coronavirus 2 (SARS-CoV2) and coronavirus disease-2019 (COVID-19): The epidemic and the challenges. Int J Antimicrob Agents. 2020; 55:105924. https://doi.org/10.1016/j.ijantimicag.2020.105924 PMID:32081636

2. Xiao F, Tang M, Zheng X, Liu Y, Li X, Shan H. Evidence for Gastrointestinal Infection of SARS-CoV-2. Gastroenterology. 2020; 158:1831-33.e3. https://doi.org/10.1053/i.gastro.2020.02.055 PMID:32142773

3. Li H, Zhou Y, Zhang $M$, Wang $H$, Zhao $Q$, Liu J. Updated Approaches against SARS-CoV-2. Antimicrob Agents Chemother. 2020; 64:e00483-20. https://doi.org/10.1128/AAC.00483-20 PMID:32205349

4. Santos J, Brierley S, Gandhi MJ, Cohen MA, Moschella PC, Declan AB. Repurposing Therapeutics for Potential Treatment of SARS-CoV-2: A Review. Viruses. 2020; 12:705. https://doi.org/10.3390/v12070705 PMID:32629804

5. Gosain R, Abdou Y, Singh A, Rana N, Puzanov I, Ernstoff MS. COVID-19 and Cancer: a Comprehensive Review. Curr Oncol Rep. 2020; 22:53. https://doi.org/10.1007/s11912-020-00934-7 PMID:32385672

6. Gentile D, Donadon M, Lleo A, Aghemo A, Roncalli M, di Tommaso L, Torzilli G. Surgical Treatment of Hepatocholangiocarcinoma: A Systematic Review. Liver Cancer. 2020; 9:15-27. https://doi.org/10.1159/000503719 PMID:32071906

7. Sia D, Villanueva A, Friedman SL, Llovet JM. Liver Cancer Cell of Origin, Molecular Class, and Effects on Patient Prognosis. Gastroenterology. 2017; 152: 745-61. https://doi.org/10.1053/i.gastro.2016.11.048 PMID:28043904

8. Li T. Diagnosis and clinical management of severe acute respiratory syndrome Coronavirus 2 (SARS-CoV2) infection: an operational recommendation of Peking Union Medical College Hospital (V2.0). Emerg Microbes Infect. 2020; 9:582-85. https://doi.org/10.1080/22221751.2020.1735265 PMID:32172669

9. Amanat F, Krammer F. SARS-CoV-2 Vaccines: Status Report. Immunity. 2020; 52:583-89. 
https://doi.org/10.1016/j.immuni.2020.03.007 PMID:32259480

10. Amaddeo $G$, Brustia R, Allaire $M$, Lequoy $M$, Hollande C, Regnault H, Blaise L, Ganne-Carrié N, Séror O, Larrey E, Lim C, Scatton O, El Mouhadi S, et al, and Paris Liver Cancer Group. Impact of COVID-19 on the management of hepatocellular carcinoma in a highprevalence area. JHEP Rep. 2021; 3:100199. https://doi.org/10.1016/i.jhepr.2020.100199 PMID: $\underline{3163949}$

11. Zeng G, Gill US, Kennedy PT. Prioritisation and the initiation of HCC surveillance in CHB patients: lessons to learn from the COVID-19 crisis. Gut. 2020; 69:1907-12. https://doi.org/10.1136/gutjnl-2020-321627 PMID: $\underline{32451325}$

12. Bar-El Dadon S, Reifen R. Vitamin $A$ and the epigenome. Crit Rev Food Sci Nutr. 2017; 57:2404-11. https://doi.org/10.1080/10408398.2015.1060940 PMID:26565606

13. Dawson MI. The importance of vitamin A in nutrition. Curr Pharm Des. 2000; 6:311-25. https://doi.org/10.2174/1381612003401190 PMID:10637381

14. Niles RM. Vitamin A and cancer. Nutrition. 2000; 16:573-76.

https://doi.org/10.1016/s0899-9007(00)00347-6 PMID:10906560

15. Stephensen CB. Vitamin A, infection, and immune function. Annu Rev Nutr. 2001; 21:167-92. https://doi.org/10.1146/annurev.nutr.21.1.167 PMID:11375434

16. Brown CC, Noelle RJ. Seeing through the dark: New insights into the immune regulatory functions of vitamin A. Eur J Immunol. 2015; 45:1287-95. https://doi.org/10.1002/eji.201344398 PMID:25808452

17. Ross AC. Vitamin A and retinoic acid in $T$ cell-related immunity. Am J Clin Nutr. 2012; 96:1166S-72S. https://doi.org/10.3945/ajcn.112.034637 PMID:23053562

18. Mondul AM, Weinstein SJ, Albanes D. Vitamins, metabolomics, and prostate cancer. World J Urol. 2017; 35:883-93.

https://doi.org/10.1007/s00345-016-1878-3

PMID:27339624

19. Terasaki T, Shimosato $Y$, Nakajima $T$, Tsumuraya $M$, Ichinose $\mathrm{H}$, Nagatsu T, Kato K. Reversible squamous cell characteristics induced by vitamin A deficiency in a small cell lung cancer cell line. Cancer Res. 1987; 47:3533-37.

PMID:2438038
20. Lan QY, Zhang YJ, Liao GC, Zhou RF, Zhou ZG, Chen YM, Zhu HL. The Association between Dietary Vitamin A and Carotenes and the Risk of Primary Liver Cancer: A Case-Control Study. Nutrients. 2016; 8:624. https://doi.org/10.3390/nu8100624 PMID:27727160

21. Li R, Ma X, Song Y, Zhang Y, Xiong W, Li L, Zhou L. Anticolorectal cancer targets of resveratrol and biological molecular mechanism: Analyses of network pharmacology, human and experimental data. J Cell Biochem. 2019; 120:11265-73.

https://doi.org/10.1002/icb.28404 PMID:30719773

22. Ge B, Guo C, Liang Y, Liu M, Wu K. Network analysis, and human and animal studies disclose the anticystitis glandularis effects of vitamin C. Biofactors. 2019; 45:912-19. https://doi.org/10.1002/biof.1558 PMID:31469455

23. Zhou R, Wu K, Su M, Li R. Bioinformatic and experimental data decipher the pharmacological targets and mechanisms of plumbagin against hepatocellular carcinoma. Environ Toxicol Pharmacol. 2019; 70:103200.

https://doi.org/10.1016/i.etap.2019.103200 PMID:31158732

24. Li R, Guo C, Li Y, Liang X, Yang L, Huang W. Therapeutic target and molecular mechanism of vitamin C-treated pneumonia: a systematic study of network pharmacology. Food Funct. 2020; 11:4765-72. https://doi.org/10.1039/d0fo00421a PMID:32420559

25. Li R, Guo C, Li Y, Qin Z, Huang W. Therapeutic targets and signaling mechanisms of vitamin $\mathrm{C}$ activity against sepsis: a bioinformatics study. Brief Bioinform. 2021; 22:bbaa079.

https://doi.org/10.1093/bib/bbaa079 PMID:32393985

26. Cooper LA, Demicco EG, Saltz JH, Powell RT, Rao A, Lazar AJ. PanCancer insights from The Cancer Genome Atlas: the pathologist's perspective. J Pathol. 2018; 244:512-24.

https://doi.org/10.1002/path.5028 PMID:29288495

27. Liu B, Liu J, Liu K, Huang H, Li Y, Hu X, Wang K, Cao H, Cheng $Q$. A prognostic signature of five pseudogenes for predicting lower-grade gliomas. Biomed Pharmacother. 2019; 117:109116.

https://doi.org/10.1016/i.biopha.2019.109116 PMID:31247469

28. Wu K, Wei $P$, Liu $M$, Liang $X$, Su M. To reveal pharmacological targets and molecular mechanisms of curcumol against interstitial cystitis. J Adv Res. 2019; 20:43-50.

https://doi.org/10.1016/i.jare.2019.05.003 PMID:31193808

29. Li R, Song $Y$, Ji Z, Li L, Zhou L. Pharmacological biotargets and the molecular mechanisms of 
oxyresveratrol treating colorectal cancer: Network and experimental analyses. Biofactors. 2020; 46:158-67. https://doi.org/10.1002/biof.1583 PMID:31647596

30. Su M, Guo C, Liu M, Liang X, Yang B. Therapeutic targets of vitamin $C$ on liver injury and associated biological mechanisms: A study of network pharmacology. Int Immunopharmacol. 2019; 66:383-87. https://doi.org/10.1016/i.intimp.2018.11.048 PMID:30530052

31. Li J, Guo C, Lu X, Tan W. Anti-colorectal cancer biotargets and biological mechanisms of puerarin: Study of molecular networks. Eur J Pharmacol. 2019; 858:172483.

https://doi.org/10.1016/i.ejphar.2019.172483 PMID:31233753

32. Liang $Y$, Zhou $R$, Liang $X$, Kong $X$, Yang $B$. Pharmacological targets and molecular mechanisms of plumbagin to treat colorectal cancer: A systematic pharmacology study. Eur J Pharmacol. 2020; 881:173227.

https://doi.org/10.1016/i.ejphar.2020.173227 PMID:32505664

33. Chong J, Soufan O, Li C, Caraus I, Li S, Bourque G, Wishart DS, Xia J. MetaboAnalyst 4.0: towards more transparent and integrative metabolomics analysis. Nucleic Acids Res. 2018; 46:W486-94. https://doi.org/10.1093/nar/gky310 PMID:29762782

34. Giangola M, Siskind S, Faliks B, Dela Cruz R, Lee A, Shebes M, Ritter G, Prince J, Coppa G, Barrera R, Patel $V$. Applying triage principles of mass casualty events to the SARS-CoV-2 pandemic: From the perspective of the acute care surgeons at Long Island Jewish Medical Center in the COVID epicenter of the United States. Surgery. 2020; 168:408-10.

https://doi.org/10.1016/i.surg.2020.06.004 PMID: 32684335

35. Roussel Y, Giraud-Gatineau A, Jimeno MT, Rolain JM, Zandotti C, Colson P, Raoult D. SARS-CoV-2: fear versus data. Int J Antimicrob Agents. 2020; 55:105947. https://doi.org/10.1016/i.ijantimicag.2020.105947 PMID:32201354

36. Renzi C, Kaushal A, Emery J, Hamilton W, Neal RD, Rachet B, Rubin G, Singh H, Walter FM, de Wit NJ, Lyratzopoulos G. Comorbid chronic diseases and cancer diagnosis: disease-specific effects and underlying mechanisms. Nat Rev Clin Oncol. 2019; 16:746-61.

https://doi.org/10.1038/s41571-019-0249-6 PMID:31350467

37. Chen DS, Mellman I. Elements of cancer immunity and the cancer-immune set point. Nature. 2017; 541: $321-30$ https://doi.org/10.1038/nature21349 PMID:28102259

38. Zhou L, Liu K, Liu HG. [Cause analysis and treatment strategies of "recurrence" with novel coronavirus pneumonia (COVID-19) patients after discharge from hospital]. Zhonghua Jie He He Hu Xi Za Zhi. 2020; 43:281-84. https://doi.org/10.3760/cma.j.cn112147-2020022900219 PMID:32118391

39. Siegel RL, Miller KD, Jemal A. Cancer statistics, 2020. CA Cancer J Clin. 2020; 70:7-30. https://doi.org/10.3322/caac.21590 PMID:31912902

40. Harcourt J, Tamin A, Lu X, Kamili S, Sakthivel SK, Murray J, Queen K, Tao Y, Paden CR, Zhang J, Li Y, Uehara $A$, Wang $H$, et al. Severe Acute Respiratory Syndrome Coronavirus 2 from Patient with Coronavirus Disease, United States. Emerg Infect Dis. 2020; 26:1266-73.

https://doi.org/10.3201/eid2606.200516 PMID: $\underline{32160149}$

41. Wang F, Chang C, Li R, Zhang Z, Jiang H, Zeng N, Li D, Chen L, Xiao $Y$, Chen W, Wang Q. Retinol binding protein 4 mediates MEHP-induced glucometabolic abnormalities in HepG2 cells. Toxicology. 2019; 424:152236.

https://doi.org/10.1016/j.tox.2019.06.007 PMID:31228551

42. Taylor ME. Structure and function of the macrophage mannose receptor. Results Probl Cell Differ. 2001; 33:105-21.

https://doi.org/10.1007/978-3-540-46410-5 6 PMID:11190670

43. Cardoso CC, Pereira AC, de Sales Marques C, Moraes $\mathrm{MO}$. Leprosy susceptibility: genetic variations regulate innate and adaptive immunity, and disease outcome. Future Microbiol. 2011; 6:533-49. https://doi.org/10.2217/fmb.11.39 PMID:21585261

44. Souza CO, Gardinassi LG, Rodrigues V, Faccioli LH. Monocyte and Macrophage-Mediated Pathology and Protective Immunity During Schistosomiasis. Front Microbiol. 2020; 11:1973.

https://doi.org/10.3389/fmicb.2020.01973 PMID:32922381

45. Brafman DA, Phung C, Kumar N, Willert K. Regulation of endodermal differentiation of human embryonic stem cells through integrin-ECM interactions. Cell Death Differ. 2013; 20:369-81.

https://doi.org/10.1038/cdd.2012.138 PMID:23154389

46. Bristow MR, Zisman LS, Altman NL, Gilbert EM, Lowes BD, Minobe WA, Slavov D, Schwisow JA, 
Rodriguez EM, Carroll IA, Keuer TA, Buttrick PM, Kao DP. Dynamic Regulation of SARS-Cov-2 Binding and Cell Entry Mechanisms in Remodeled Human Ventricular Myocardium. JACC Basic Transl Sci. 2020; 5:871-83.

https://doi.org/10.1016/i.jacbts.2020.06.007

PMID:32838074

47. Islam AB, Khan MA, Ahmed R, Hossain MS, Kabir SM, Islam MS, Siddiki AM. Transcriptome of nasopharyngeal samples from COVID-19 patients and a comparative analysis with other SARS-CoV-2 infection models reveal disparate host responses against SARSCoV-2. J Transl Med. 2021; 19:32.

https://doi.org/10.1186/s12967-020-02695-0

PMID:33413422

48. Liu C, Zhao Y, Xi H, Jiang J, Yu Y, Dong W. The Membrane Interaction of Alpha-Synuclein. Front Cell Neurosci. 2021; 15:633727.

https://doi.org/10.3389/fncel.2021.633727

PMID:33746714

49. Ait Wahmane S, Achbani A, Ouhaz Z, Elatiqi M, Belmouden A, Nejmeddine $M$. The Possible Protective Role of $\alpha$-Synuclein Against Severe Acute Respiratory Syndrome Coronavirus 2 Infections in Patients With Parkinson's Disease. Mov Disord. 2020; 35:1293-94.

https://doi.org/10.1002/mds.28185

PMID:32519352

50. Cecerska-Heryć E, Surowska O, Heryć R, Serwin N, Napiontek-Balińska S, Dołęgowska B. Are antioxidant enzymes essential markers in the diagnosis and monitoring of cancer patients - A review. Clin Biochem. 2021; 93:1-8.

https://doi.org/10.1016/i.clinbiochem.2021.03.008 PMID:33773993

51. Shi M, Li ZY, Zhang LM, Wu XY, Xiang SH, Wang YG, Zhang YQ. Hsa_circ_0007456 regulates the natural killer cell-mediated cytotoxicity toward hepatocellular carcinoma via the miR-6852-3p/ICAM-1 axis. Cell Death Dis. 2021; 12:94.

https://doi.org/10.1038/s41419-020-03334-8

PMID:33462208

52. Leung MS, Chan KK, Dai WJ, Wong CY, Au KY, Wong PY, Wong CC, Lee TK, Ng IO, Kao WJ, Lo RC. Anti-tumour effects of PIM kinase inhibition on progression and chemoresistance of hepatocellular carcinoma. J Pathol. 2020; 252:65-76.

https://doi.org/10.1002/path.5492

PMID:32558942

53. Kong J, Yao C, Dong S, Wu S, Xu Y, Li K, Ji L, Shen Q, Zhang $Q$, Zhan $R$, Cui $H$, Zhou $C$, Niu $H$, et al. ICAM-1 Activates Platelets and Promotes Endothelial Permeability through VE-Cadherin after Insufficient
Radiofrequency Ablation. Adv Sci (Weinh). 2021; 8:2002228.

https://doi.org/10.1002/advs.202002228

PMID:33643788

54. Chen VL, Le AK, Podlaha O, Estevez J, Li B, Vutien P, Chang ET, Rosenberg-Hasson Y, Pflanz S, Jiang Z, Ge D, Gaggar A, Nguyen $\mathrm{MH}$. Soluble intercellular adhesion molecule- 1 is associated with hepatocellular carcinoma risk: multiplex analysis of serum markers. Sci Rep. 2017; 7:11169.

https://doi.org/10.1038/s41598-017-10498-5

PMID:28894136

55. Zhu PP, Yuan SG, Liao Y, Qin LL, Liao WJ. High level of intercellular adhesion molecule-1 affects prognosis of patients with hepatocellular carcinoma. World J Gastroenterol. 2015; 21:7254-63.

https://doi.org/10.3748/wjg.v21.i23.7254 PMID:26109813

56. Dai Y, Cui J, Gan P, Li W. Downregulation of tetrahydrobiopterin inhibits tumor angiogenesis in BALB/c-nu mice with hepatocellular carcinoma. Oncol Rep. 2016; 36:669-75.

https://doi.org/10.3892/or.2016.4850 PMID:27279530

57. Fantappiè O, Sassoli C, Tani A, Nosi D, Marchetti S, Formigli L, Mazzanti R. Mitochondria of a human multidrug-resistant hepatocellular carcinoma cell line constitutively express inducible nitric oxide synthase in the inner membrane. J Cell Mol Med. 2015; 19: 1410-17.

https://doi.org/10.1111/jcmm.12528

PMID:25691007

58. Park YH, Shin HJ, Kim SU, Kim JM, Kim JH, Bang DH, Chang KT, Kim BY, Yu DY. iNOS promotes HBx-induced hepatocellular carcinoma via upregulation of JNK activation. Biochem Biophys Res Commun. 2013; 435:244-49.

https://doi.org/10.1016/i.bbrc.2013.04.071

PMID:23643810

59. Kakehashi A, Suzuki S, Ishii N, Okuno T, Kuwae $Y$, Fujioka M, Gi M, Stefanov V, Wanibuchi $H$. Accumulation of 8-hydroxydeoxyguanosine, L-arginine and Glucose Metabolites by Liver Tumor Cells Are the Important Characteristic Features of Metabolic Syndrome and Non-Alcoholic SteatohepatitisAssociated Hepatocarcinogenesis. Int J Mol Sci. 2020; 21:7746.

https://doi.org/10.3390/ijms21207746 PMID:33092030

60. Liu Z, Tu MJ, Zhang C, Jilek JL, Zhang QY, Yu AM. A reliable LC-MS/MS method for the quantification of natural amino acids in mouse plasma: Method validation and application to a study on amino acid dynamics during hepatocellular carcinoma progression. 
J Chromatogr B Analyt Technol Biomed Life Sci. 2019; 1124:72-81.

https://doi.org/10.1016/j.jchromb.2019.05.039

PMID:31177050

61. De Matteis S, Ragusa A, Marisi G, De Domenico S, Casadei Gardini A, Bonafè M, Giudetti AM. Aberrant Metabolism in Hepatocellular Carcinoma Provides Diagnostic and Therapeutic Opportunities. Oxid Med Cell Longev. 2018; 2018:7512159. https://doi.org/10.1155/2018/7512159

PMID:30524660

62. Li L, Wang T, Li S, Chen Z, Wu J, Cao W, Wo Q, Qin X, Xu J. TDO2 Promotes the EMT of Hepatocellular Carcinoma Through Kyn-AhR Pathway. Front Oncol. 2021; 10:562823.

https://doi.org/10.3389/fonc.2020.562823

PMID:33542896 


\section{SUPPLEMENTARY MATERIALS}

\section{Supplementary Tables}

Supplementary Table 1. List of CHOL/COVID-19/VA-associated genes.

\begin{tabular}{lcccc}
\hline Query & Entrez & Symbol & Name & Comment \\
\hline BRD2 & 6046 & BRD2 & bromodomain containing 2 & 1 \\
NOS2 & 4843 & NOS2 & nitric oxide synthase 2 & 1 \\
GPT & 2875 & GPT & glutamic--pyruvic transaminase & 1 \\
MAPK1 & 5594 & MAPK1 & mitogen-activated protein kinase 1 & 1 \\
CXCR3 & 2833 & CXCR3 & C-X-C motif chemokine receptor 3 & 1 \\
ICAM1 & 3383 & ICAM1 & intercellular adhesion molecule 1 & 1 \\
CDK4 & 1019 & CDK4 & cyclin dependent kinase 4 & 1 \\
CAT & 847 & CAT & catalase & 1 \\
TMPRSS13 & 84000 & TMPRSS13 & transmembrane serine protease 13 & 1 \\
\hline
\end{tabular}


Supplementary Table 2. Alteration of biological processes.

\begin{tabular}{|c|c|c|c|c|c|c|c|c|c|c|}
\hline ONTOLOGY & ID & Description & GeneRatio & BgRatio & pvalue & p.adjust & qvalue & geneID & Count & Remark \\
\hline BP & GO:0070482 & $\begin{array}{c}\text { response to oxygen } \\
\text { levels }\end{array}$ & $4 / 9$ & $394 / 18670$ & $2.26 \mathrm{E}-05$ & 0.001975 & 0.001018 & $\begin{array}{l}\text { NOS2/ICAM1/ } \\
\text { CDK4/CAT }\end{array}$ & 4 & Inflammatory \\
\hline BP & GO:0036296 & $\begin{array}{l}\text { response to increased } \\
\text { oxygen levels }\end{array}$ & $2 / 9$ & $28 / 18670$ & 7.76E-05 & 0.004923 & 0.002539 & CDK4/CAT & 2 & Inflammatory \\
\hline BP & GO:0072593 & $\begin{array}{c}\text { reactive oxygen } \\
\text { species metabolic } \\
\text { process }\end{array}$ & $3 / 9$ & $284 / 18670$ & 0.000273 & 0.013629 & 0.007029 & $\begin{array}{l}\text { NOS2/ICAM1/ } \\
\text { CAT }\end{array}$ & 3 & Inflammatory \\
\hline BP & GO: 1903409 & $\begin{array}{c}\text { reactive oxygen } \\
\text { species biosynthetic } \\
\text { process }\end{array}$ & $2 / 9$ & $122 / 18670$ & 0.00148 & 0.024627 & 0.012702 & NOS2/ICAM1 & 2 & Inflammatory \\
\hline BP & GO:0072678 & $\mathrm{T}$ cell migration & $2 / 9$ & $65 / 18670$ & 0.000423 & 0.01512 & 0.007798 & CXCR3/ICAM1 & 2 & Immunity \\
\hline BP & GO:0006625 & $\begin{array}{l}\text { protein targeting to } \\
\text { peroxisome }\end{array}$ & $2 / 9$ & $68 / 18670$ & 0.000463 & 0.01512 & 0.007798 & NOS2/CAT & 2 & Immunity \\
\hline BP & GO:0043574 & peroxisomal transport & $2 / 9$ & $69 / 18670$ & 0.000477 & 0.01512 & 0.007798 & NOS2/CAT & 2 & Immunity \\
\hline BP & GO:0001666 & response to hypoxia & $3 / 9$ & $359 / 18670$ & 0.000543 & 0.01634 & 0.008427 & $\begin{array}{c}\text { NOS2/ICAM1/ } \\
\text { CAT }\end{array}$ & 3 & Immunity \\
\hline BP & GO:0036293 & $\begin{array}{l}\text { response to decreased } \\
\text { oxygen levels }\end{array}$ & $3 / 9$ & $370 / 18670$ & 0.000593 & 0.01634 & 0.008427 & $\begin{array}{c}\text { NOS2/ICAM1/ } \\
\text { CAT }\end{array}$ & 3 & Immunity \\
\hline BP & GO:0001910 & $\begin{array}{l}\text { regulation of leukocyte } \\
\text { mediated cytotoxicity }\end{array}$ & $2 / 9$ & $78 / 18670$ & 0.000609 & 0.01634 & 0.008427 & NOS2/ICAM1 & 2 & Immunity \\
\hline BP & GO:0007031 & $\begin{array}{l}\text { peroxisome } \\
\text { organization }\end{array}$ & $2 / 9$ & $81 / 18670$ & 0.000656 & 0.016763 & 0.008646 & NOS2/CAT & 2 & Immunity \\
\hline BP & GO:0001906 & cell killing & $2 / 9$ & $168 / 18670$ & 0.00278 & 0.038807 & 0.020015 & NOS2/ICAM1 & 2 & Immunity \\
\hline BP & GO:0002685 & $\begin{array}{l}\text { regulation of leukocyte } \\
\text { migration }\end{array}$ & $2 / 9$ & $196 / 18670$ & 0.003761 & 0.046872 & 0.024175 & CXCR3/ICAM1 & 2 & Immunity \\
\hline BP & GO:0071346 & $\begin{array}{l}\text { cellular response to } \\
\text { interferon-gamma }\end{array}$ & $2 / 9$ & $180 / 18670$ & 0.003183 & 0.043191 & 0.022276 & NOS2/ICAM1 & 2 & Cytokine \\
\hline BP & GO:0034341 & $\begin{array}{l}\text { response to interferon- } \\
\text { gamma }\end{array}$ & $2 / 9$ & $199 / 18670$ & 0.003874 & 0.047438 & 0.024467 & NOS2/ICAM1 & 2 & Cytokine \\
\hline
\end{tabular}


Supplementary Table 3. Alteration of KEGG pathways.

\begin{tabular}{|c|c|c|c|c|c|c|c|c|c|}
\hline ID & Description & GeneRatio & BgRatio & pvalue & p.adjust & qvalue & geneID & Count & Remark \\
\hline hsa05167 & $\begin{array}{l}\text { Kaposi sarcoma-associated } \\
\text { herpesvirus infection }\end{array}$ & $3 / 7$ & $189 / 8047$ & 0.000416 & 0.014676 & 0.009751 & MAPK1/ICAM1/CDK4 & 3 & Viral \\
\hline hsa05166 & $\begin{array}{c}\text { Human T-cell leukemia virus } 1 \\
\text { infection }\end{array}$ & $3 / 7$ & $219 / 8047$ & 0.000642 & 0.015083 & 0.010021 & MAPK1/ICAM1/CDK4 & 3 & Viral \\
\hline hsa05145 & Toxoplasmosis & $2 / 7$ & $112 / 8047$ & 0.003852 & 0.025864 & 0.017185 & NOS2/MAPK1 & 2 & Viral \\
\hline hsa05169 & Epstein-Barr virus infection & $2 / 7$ & $202 / 8047$ & 0.012117 & 0.049748 & 0.033054 & ICAM1/CDK4 & 2 & Viral \\
\hline hsa05203 & Viral carcinogenesis & $2 / 7$ & $204 / 8047$ & 0.012349 & 0.049748 & 0.033054 & MAPK1/CDK4 & 2 & Viral \\
\hline hsa04146 & Peroxisome & $2 / 7$ & $83 / 8047$ & 0.002134 & 0.021497 & 0.014283 & NOS2/CAT & 2 & Immunity \\
\hline hsa04660 & $\mathrm{T}$ cell receptor signaling pathway & $2 / 7$ & $104 / 8047$ & 0.00333 & 0.025864 & 0.017185 & MAPK1/CDK4 & 2 & Immunity \\
\hline hsa04926 & Relaxin signaling pathway & $2 / 7$ & $129 / 8047$ & 0.00508 & 0.029527 & 0.019619 & NOS2/MAPK1 & 2 & Signaling \\
\hline hsa04068 & FoxO signaling pathway & $2 / 7$ & $131 / 8047$ & 0.005235 & 0.029527 & 0.019619 & MAPK1/CAT & 2 & Signaling \\
\hline hsa04371 & Apelin signaling pathway & $2 / 7$ & $137 / 8047$ & 0.005713 & 0.030985 & 0.020587 & NOS2/MAPK1 & 2 & Signaling \\
\hline hsa04062 & Chemokine signaling pathway & $2 / 7$ & $189 / 8047$ & 0.010662 & 0.045556 & 0.030269 & MAPK1/CXCR3 & 2 & Signaling \\
\hline
\end{tabular}

